\title{
Grand challenges in Earth science: research toward a sustainable environment
}

\author{
Valerio Acocella * \\ Dipartimento di Scienze, Università Roma Tre, Roma, Italy
}

Keywords: Earth science, research, environment, hazard, resource

\section{INTRODUCTION}

Earth science is a broad term referring to the fields of science dealing with our planet. It involves studies on the lithosphere (including geology, geophysics, geochemistry, and geography), the hydrosphere (including hydrology and marine, ocean, and cryospheric sciences) and the atmosphere (including meteorology and climatology). As such, Earth science consists of a broad spectrum of interconnected physical, chemical, and biological disciplines dealing with processes which have been occurring on our world for billions of years, from the subatomic to the planetary scale.

The stature of Earth science has grown with each new decade, defining the history of life, unveiling the evolution of the planetary surface, quantifying natural hazards, locating mineral and energy resources and characterizing the climate system. This, supported by continuing technical and theoretical improvements, has allowed reaching an unprecedented understanding of countless processes. The capabilities of the Earth science subdisciplines have advanced to document the geological record of terrestrial changes, understand how life evolved, observe active processes from the core to the surface, make more realistic simulations of complex dynamic processes and start forecasting. Many important discoveries, as for example the plate tectonics theory or the definition of the hydrological cycle, have been achieved gradually, from the merging of several important and independent studies (Dooge, 2001; Oreskes, 2013). This progression has also brought to the recognition and verification of the need to establish broad connections and integrations between different subdisciplines, a major advance in Earth science especially over the past decade (NAP, 2012). Consider for example the potential of studies exploring the intimate relationships between climate, surface processes (including hydrology, physical and chemical denudation, sedimentary deposition, flooding) and tectonics (from the evolution of mountain ranges to earthquakes). Or the research at the intersection of geomorphology, hydrology and ecology, which delivers new insights into the mechanisms of landscape-ecosystem interactions, including the rates of soil formation or denudation in given landscapes. This multidisciplinarity points out to an innovative, first-order level of research and understanding, where the Earth is considered as a single system, with properties and behavior that are characteristic of the system as a whole, including critical thresholds, nonlinearities, tele-connections, and unresolvable uncertainties.

Looking forward to the next decade and beyond, the role of Earth science studies for the Received: 10 September 2015 Accepted: 26 October 2015 Published: 02 November 2015

Citation:

Acocella V (2015) Grand challenges in Earth science: research toward a development of our planet will expand substantially. Earth science will become increasingly prominent as humanity confronts daunting challenges in finding natural resources to sustain Earth's burgeoning population, in mitigating natural hazards that impact life and infrastructures, and, more in general, in achieving sustainable environmental stewardship (NAP, 2012). Earth science research will have to improve the management of natural resources (as water, raw materials and energy) and hazards, supporting prosperous and secure societies and developing new industries for economic growth. Earth science is in fact the foundation of the exploration and the responsible use of our natural resources through an understanding of 
the surface and subsurface. Much of the energy sector depends on understanding processes and monitoring in the subsurface, including the extraction of coal, oil, gas and shale gas and geothermal fluids, as well as carbon capture and storage and nuclear waste storage (ICSU, 2010). The management of natural resources should be also accompanied by the forecast and management of natural hazards (including earthquakes, tsunamis, cyclones, floods, sea level rise, eruptions, drought), increasingly exposing the growing population and infrastructures. While hazards are inevitable, the worst of their consequences are not: loss of life and infrastructure can be minimized through monitoring and modeling, in the frame of adequate longer-term prevention and shorterterm forecast. The diagram in Figure 1 shows that, while the frequency of natural hazards (and the related amount of exposed population) has increased in the last century, the death toll has significantly decreased, highlighting the impact of prevention in mitigating risk.

The management of natural resources and hazards should be, in turn, coupled by a sustainable environment, especially aimed at preserving: (a) the water cycle, altered by reservoir construction, agriculture, groundwater extraction, and urbanization, at places responsible for significant groundwater depletion (Wada et al., 2010); (b) the carbon cycle, central to climate but heavily affected by anthropogenic greenhouse gas emissions and land use, and also recent geo-engineering practices aimed at reducing the human impact on climate (Bala, 2009; Finzi et al., 2011); (c) the Earth's surface, undergoing transformations in its physical, chemical, and biological state, with accelerated soil erosion and mobilization and deposition of metals and toxins; (d) coastal areas, hosting $>60 \%$ of the world's population and, as subject to forcing from both ocean and land processes, experiencing coupling of geomorphic, hydrological, ecological, climatic, and biogeochemical phenomena.

Clearly, the Earth sciences in the twenty-first century have great potential: on the one side, in deepening our knowledge of the functioning of the Earth system and its critical thresholds and, on the other side, in developing response strategies to global changes (ICSU, 2010). However, despite the accelerating importance and pivotal role in the development of society and environment, the reality is that Earth science currently still receives less attention than warranted at all levels in the education systems and in the funding supports for research (NAP, 2012). Indeed, Earth science can deliver its best to society and environment through research with a twofold objective: (1) allowing the understanding of the processes operating within the Earth system and in its many subdisciplines; (2) providing the crucial knowledge for the discovery, use, and conservation of natural resources, the definition and mitigation of the natural hazards, the geotechnical support of commercial and infrastructure development and the stewardship of the environment (NAP, 2012). Therefore, research should be not only devoted at understanding the present and the environmentally challenging future, but also our past. Earth's environmental systems have experienced geochemical, climatic, and biotic change, with conditions in the distant past remarkably different from those of the Holocene, when largely benign climatic conditions fostered human civilizations. Thus,

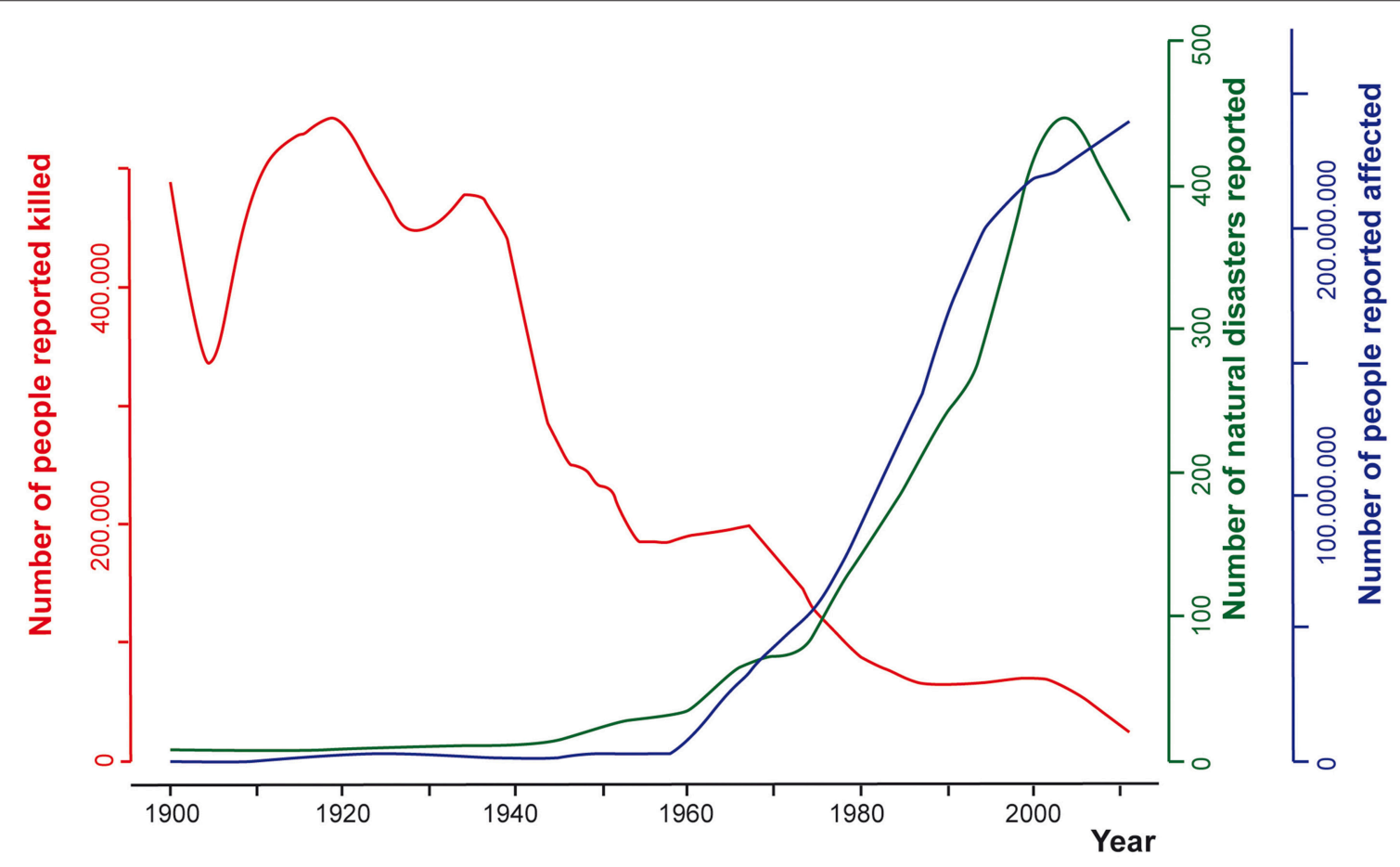

FIGURE 1 | Relationships between the frequency of natural disasters, the amount of exposed population and the related death toll since 1900. The overall decrease in deaths, despite the significant increase in disasters, underlines the crucial importance of prevention in mitigating risk (from the OFDA/CRED Natural Disaster Database, www.emdat.be). 
understanding past geosphere-biosphere behavior is a potent approach to anticipating how linked physical, chemical, and biological processes that characterize Earth's surface may be impacted by and respond to human activity.

\section{THE CHALLENGES}

Under these premises, the main challenges for Earth science may be defined. Many major challenges of several subdisciplines of Earth science have been already recently proposed, in general documents (ESA, 2013) or in more detail, as in dedicated papers on seismology (Lay, 2009), geodynamics (Olsen et al., 2010), terrestrial microbiology (Stein and Nicol, 2011), atmospheric science (Gimeno, 2013), structural geology and tectonics (Gudmundsson, 2013), geomagnetism and paleomagnetism, (Kodama, 2013), climate (Beniston, 2013), volcanology (Acocella, 2014), environmental informatics (Kokhanovsky, 2014), biogeochemistry (Achterberg, 2014), paleontology (Reisz and Sues, 2015), biogeoscience (Eglinton, 2015), and Quaternary geology and geomorphology (Forman and Stinchcomb, 2015).

Here I aim at considering the major challenges from a higher level, potentially involving all the subdisciplines and studies of Earth science (Figure 2). These grand challenges regard different aspects of research in Earth science, crucial for both research and science policy. They should not be considered as separate entities, as none of the challenges alone can be fully addressed without significant progress in addressing the other challenges, as also

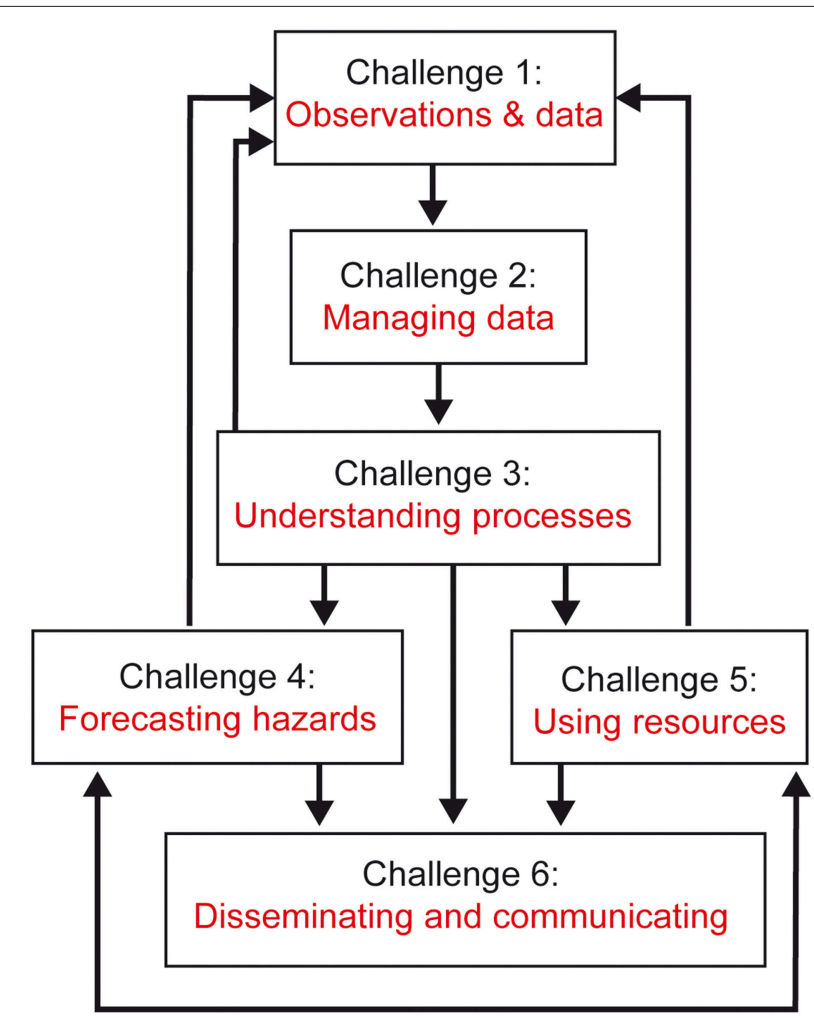

FIGURE 2 | Diagram summarizing the six proposed grand challenges of Earth science, as well as their relationships. indicated in Figure 2. The six major challenges for Earth science in the first part of the twenty-first century are listed below.

\section{Challenge 1: Expanding Global Observation Networks and Data Archives}

This challenge focuses on promoting, developing and integrating the collection of the observation systems and data archives needed to manage global and regional aspects, including environmental changes.

Observations, or more in general data, are the first crucial ingredient on which research is based and thus their collection and promotion must be at the base of any grand challenge. Creating an innovative, integrated, coordinated, and useful generation of observations is thus the first challenge for Earth science. Observations, both quantitative and qualitative, should be multidisciplinary and focused toward global or regional systems, encompassing both natural and social features. Also, they should be of high enough resolution and carry comprehensive time-series information, to detect any change and assess vulnerability and resilience. Finally, they should provide full and open access to data (see also challenge 2) and be cost effective. An appropriate example is given by the rapid progress of satellite Earth observation science. This, coupled with the increasing use of new technologies, has allowed maximizing (i.e., expanding and integrating) the amount of information on Earth science. This challenge, in addition to the identification of the fundamental scientific questions to be addressed, requires integrated and coordinated policies on the longer-term (decades). Important investments are already being made to build effective global and regional monitoring systems and to ensure their international coordination (as the Global Earth Observation System of Systems, GEOSS; http://www.earthobservations.org/ geoss.php and its implementation programmes, as for example Copernicus; http://land.copernicus.eu). These initiatives should be further promoted and supported, also at any regional scale. The most appropriate collection of data may be guided by the feedback promoted by the understanding of the related processes, the forecast of hazards and use of resources (Figure 2).

\section{Challenge 2: Handling and Using the Multidisciplinary Observations}

This challenge focuses on the importance to appropriately manage (organizing, storing, handling) the collected observations, particularly those of multidisciplinary nature, in order to make them readily available to and used by the scientific community.

The increasingly growing and already vast amount of data collected in Earth science in the last decades, especially that relative to monitoring general processes and natural hazards (challenge 1), is largely underexploited, as usually fragmented, dispersed or poorly accessible and non-uniform. This condition constitutes a severe limitation for the development of research. Proper use and exploitation of these data require longlasting, innovative and appropriate policies and infrastructures of collection, conservation, sharing and use, based on an international and effective coordination of observations, protocols of standard data storage and analysis. Successful 
examples of international data integration are the EPOS and OGC initiatives. The European EPOS framework (http://www. epos-eu.org) integrates solid Earth data from satellite, seismic, surface dynamics, volcanic and oceanic observations with experimental and analytical laboratories, uniting researchers as a virtual community. EPOS works by integrating existing national infrastructures to enhance access to the data and promote its use in innovative ways. While the links being developed by EPOS will benefit researchers initially, stakeholders in industry, business and society will also benefit. The OGC (Open Geospatial Consortium; http://www.opengeospatial.org) is an international initiative to share geospatial data, committed to making quality open standards for the global geospatial community.

\section{Challenge 3: Understanding General Multidisciplinary Processes}

This challenge focuses on understanding (i.e., unraveling the processes behind) the major global and regional processes involving different subdisciplines in Earth science.

Each subdiscipline is characterized by a variable amount of interconnected basic processes, whose understanding allows explaining its general lines and adequately relating this to the nearby subdisciplines. While the general lines of many processes within each subdiscipline of Earth science have been understood or are on their way to be sufficiently defined, a general need to integrate this acquired knowledge (challenges 1 and 2) toward the understanding of first-order processes, at the regional or global scale, is now emerging. These first-order processes, aimed at responding to the complex primary needs of our society, typically involve observations and knowledge from multiple subdisciplines. Examples are the processes related to multihazards, including the causal relationships between different types of hazard and their outcome, and the above mentioned relations between climate, landscape and tectonic activity in shaping the Earth's surface. The definition and understanding of global multidisciplinary processes is a primary concern for research institutions and society and, as such, it requires significant international coordination and cooperation.

\section{Challenge 4: Forecasting Hazards}

This challenge focuses on improving the usefulness of forecasts of future adverse environmental conditions and their consequences for humans and the environment. Here "forecasting" is meant in the broadest sense, including both the short-term events (years or less) and the longer-term projections (decades).

Despite the many important, at times crucial, attempts, forecasting natural hazards is in general at its infancy stage and currently considered in a few countries only. A modern and useful forecast should be responsive to the needs of society and decision-makers for information at adequate spatial and temporal scales and, as such, it should be timely, accurate, and reliable. Natural hazards may manifest on the shortterm, suddenly and without sufficient warning, as earthquakes, tsunamis, floods, cyclones, volcanic eruptions, or may build-up trough processes active on the longer-term, as sea level rise, drought and climatic changes. In this last case, an important example of international body devoted at the assessment of climate change is the Intergovernmental Panel for Climate
Change, or IPCC (http://www.ipcc.ch). Although we may not be able to accurately forecast beyond a time horizon of a few decades, there is still significant potential to improve our ability to use scenarios and simulations to anticipate the impacts of a given set of conditions. In most cases, however, we will not be able to predict absolutely, but only to forecast probabilistically: we can forecast the most likely outcome(s) and assign this(these) a level of certainty to that prediction.

Progress in forecasting requires several steps. These include advances in: (a) collecting the necessary data (see challenge 1); (b) an interdisciplinary framework for analysis (challenge 2); (c) understanding and modeling the fundamentals of physical, chemical and biological processes (challenge 3); (d) creating and promoting the infrastructures to face natural hazards (observatories, agencies, departments; challenge 4). Forecasting models and analyses of global and regional environmental change may provide direct support to governance and management only under these premises.

\section{Challenge 5: Using Resources}

This challenge focuses on an adequate (i.e., sustainable, with preservation) use of the available natural resources, including water, materials and energy.

In addition to natural hazards (challenge 4), the availability of resources is the major environmental challenge our planet has to face. The overshoot day (i.e., when humanity's demand on nature exceeds what Earth's ecosystems can renew in a year) anticipates year by year, leaving humanity with an increasing ecological debt and fewer resources available. These include water, raw materials and energy (as coal, oil, gas and shale gas, minerals, geothermal fluids). Also related to the management of resources are the storage of nuclear waste and carbon dioxide. For example, reserves of minerals are being exhausted and worries about access to raw materials, including basic and strategic minerals, are increasing. The rise in the price of several important metals, as copper, has prompted some industrialized countries to initiate concerted activities to ensure access to strategic minerals. Recycling, resource efficiency and the search for alternative materials are essential, but most specialists agree that this will not suffice and that there is a need to find new primary deposits. Most Earth science disciplines are structured to respond to this challenge, identifying the location and distribution of resources, planning their use and collaborating at their exploitation. However, as global challenges require global efforts, in addition to the development of research, technological advances and timely and coordinated international policies, closely involving decision makers and stakeholders, are required to adequately meet this challenge.

\section{Challenge 6: Disseminating and Communicating}

This challenge focuses on the dissemination and communication to the society of the results, achievements and general outcome of the research in Earth science.

As mentioned in each of the grand challenges above, a global challenge implies a global effort, where researchers should integrate and coordinate with decision makers at all levels of societies. This requires that the importance and outcome of the research in Earth science is appropriately communicated 
and disseminated, to adequately inform decision makers and to properly value the role of Earth science. Indeed, education and outreach through appropriate channels and media (e.g., internet, television, events of various nature) are fundamental for Earth science: inspirational research brings young people into technical careers and practical information enables informed decisionmaking. In addition, a lively and shared research culture brings innovative ideas that spread into new technological industries and brings skilled people in careers supporting society. A higher level of Earth science knowledge among authorities, educators, business and officials will lead to more effective governance.

A more specific but still important aim of dissemination and communication is to build public confidence in the renewing supplies of natural resources and in the assessment of geohazards and management of their effects. However, in Earth science it should be important to distinguish between communicating science and communicating risk to society. Communicating risk from geohazards requires understanding of the resilience of communities and an appreciation of how individuals assimilate and apply scientific information on risk and personal exposure. With this regard, an important challenge of Earth scientists is to refocus society's desire for absolute guarantees from science and replace it with an acceptance that most solutions are uncertain and will carry some level of risk and environmental consequence.

\section{CONCLUSIONS}

Humankind needs to be safe from natural hazards and wants to live comfortably, with secure supply of energy, water and

\section{REFERENCES}

Achterberg, E. P. (2014). Grand challenges in marine biogeochemistry. Front. Mar. Sci. 1:7. doi: 10.3389/fmars. 2014.00007

Acocella, V. (2014). Great Challenges in volcanology: how does the volcano factory work? Front. Volcanol. 2:10. doi: 10.3389/feart.2014. 00004

Bala, G. (2009). Problems with geoengineering schemes to combat climate change. Curr. Sci. 96, 41-48.

Beniston, M. (2013). Grand challenges in climate research. Front. Environ. Sci. 1:1. doi: $10.3389 /$ fenvs.2013.00001

Dooge, J. C. I. (2001). "Concepts of the hydrological cycle," in Ancient and Modern. International Symposium $\mathrm{OH}_{2}$ 'Origins and History of Hydrology (Dijon: Universitè de Bourgogne).

Eglinton, T. I. (2015). Grand challenges in biogeoscience. Front. Earth Sci. 3:39. doi: 10.3389/feart.2015.00039

ESA (2013). Updating the Scientific Challenges of ESA's Living Planet Programme Science Strategy. A Proposal by the ESA Earth Science Advisory Committee.

Finzi, A. C., Cole, J. J., Doney, S. C., Holland, E. A., and Jackson, R. B. (2011). Research frontiers in the analysis of coupled biogeochemical cycles. Front. Ecol. Environ. 9, 74-80. doi: 10.1890/100137

Forman, S. L., and Stinchcomb, G. E. (2015). Views on grand research challenges for Quaternary geology, geomorphology and environments. Front. Earth Sci. 3:47. doi: $10.3389 /$ feart.2015.00047

Gimeno, L. (2013). Grand challenges in atmospheric science. Front. Earth Sci. 1:1. doi: 10.3389/feart.2013.00001

Gudmundsson, A. (2013). Great challenges in structural geology and tectonics. Front. Earth Sci. 1:2. doi: 10.3389/feart.2013.00002

ICSU (2010). Earth System Science for Global Sustainability: The Grand Challenges. Paris: International Council for Science.

Kodama, K. P. (2013). Grand challenges in geomagnetism and paleomagnetism. Front. Earth Sci. 1:3. doi: 10.3389/feart.2013.00003 materials. Earth science research is the key to achieve these goals.

Earth science has played an increasingly important role in the understanding and management of our planet in the last decades. In the twenty-first century, Earth science is expected to increase further its potential, also providing crucial advice in finding resources and mitigating natural hazards, thus supporting successful and secure societies.

These objectives can be adequately reached facing the above-mentioned major challenges, which are closely related to each other. As such, they require, in addition to appropriate research, also integration and coordination at the planetary scale and close connection with decision makers, at all scales of societies.

While an important preparatory phase has been carried out in most, if not all, of these challenges, important progresses still await our scientific community, stakeholders, decision-makers and society in general to support Earth science and our planet toward a more sustainable environment.

Frontiers in Earth Science is at the forefront in this mission, trying to globally promote and deliver topmost quality research, aimed at understating our planet and using this knowledge to improve our future.

\section{ACKNOWLEDGMENTS}

Francesca Funiciello provided a useful revision on an early draft of the manuscript. Two reviewers provided very constructive and helpful comments and suggestions.

Kokhanovsky, A. (2014). Grand challenges in environmental informatics. Front. Environ. Sci. 1:5. doi: 10.3389/fenvs.2013.00005

Lay, T. (ed.). (2009). Seismological Grand Challenges in Understanding Earth's Dynamic Systems, Report to the National Science Foundation, IRIS Consortium.

NAP (2012). New Research Opportunities in the Earth Sciences at the National Science Foundation. Washington, DC: National Research Council.

Olsen, P., Bercovici, D., Buffett, B., Carlson, R., Flesch, L., Morgan, J. P., et al. (2010). Grand Challenges in Geodynamics. Outstanding Geodynamics Problems and Emerging Research Opportunities for the Earth Sciences. White Paper Prepared for the National Science Foundation.

Oreskes, N. (2013). How plate tectonics clicked. Nature 501, 27-29. doi: $10.1038 / 501027 \mathrm{a}$

Reisz, R. R., and Sues, H.-D. (2015). The challenges and opportunities for research in paleontology for the next decade. Front. Earth Sci. 3:9. doi: 10.3389/feart.2015.00009

Stein, L. Y., and Nicol, G. W. (2011). Grand challenges in terrestrial microbiology. Front. Microbiol. 2:6. doi: 10.3389/fmicb.2011.00006

Wada, Y., van Beek, L. P. H., van Kempen, C. M., Reckman, J. W. T. M., Vasak, S., and Bierkens, M. F. P. (2010). Global depletion of groundwater resources. Geophys. Res. Lett. 37, L20402. doi: 10.1029/2010gl044571

Conflict of Interest Statement: The author declares that the research was conducted in the absence of any commercial or financial relationships that could be construed as a potential conflict of interest.

Copyright (C) 2015 Acocella. This is an open-access article distributed under the terms of the Creative Commons Attribution License (CC BY). The use, distribution or reproduction in other forums is permitted, provided the original author(s) or licensor are credited and that the original publication in this journal is cited, in accordance with accepted academic practice. No use, distribution or reproduction is permitted which does not comply with these terms. 